\title{
Increasing emergency department admissions for chemsex-related intoxications in Barcelona, Spain, among people living with HIV: an observational study from 2018 to 2020
}

Gabriel Vallecillo', Alejandra Losada ${ }^{2}$, Alexy Inciarte ${ }^{3}$, Chen Jiwei ${ }^{2}$, Albert Monterde $^{2}$, Emilio Salgado ${ }^{2}$, Adriana Laura Doi ${ }^{2}$, Esther Monclus ${ }^{2}$ and Rafael Perelló ${ }^{2 *}$

\begin{abstract}
Background: Chemsex is a novel phenomenon referring to the use of drugs, including crystal methamphetamine, gammahydroxybutyric acid (GHB)/gamma-butyrolactone (GABA) and mephedrone, to facilitate, enhance, and prolong the sexual experience in men who have sex with men in large cities internationally. There is a growing concern about chemsex and fatal cases among people living with HIV on antiretroviral therapy. This study aimed to describe the clinical characteristics of chemsex-related intoxications.

Material and methods: An observational study was conducted in people living with HIV who were admitted for chemsex-related intoxications in an emergency department of a teaching hospital in Barcelona, Spain, from 2018 to 2020. Severe acute intoxications were defined according to the Poisoning Severity Score.

Results: One hundred and fifteen male patients with a median age of 35.6 \pm 7 years were included in the study:15 (13.1\%) in 2018, 32 (27.8\%) in 2019 and 68 (59.1\%) in 2020. All patients had stable housing, 107(93.0\%) were Spanish citizen and 32 (27.8\%) had mental health disorders. Median CD4 lymphocyte count was $624(500-765) \mathrm{cells} / \mathrm{mm}^{3}$ and 99 (86.1\%) had HIV-1 RNA suppression.

Poly-drug use was observed in $51(44.3 \%)$ cases and methamphetamine in $75(65,2 \%)$ and gammahydroxibutiric acid in 68 (59.1\%) were the main drugs used.

Potential drug interactions due to the inhibition of cytochrome P450 by antiviral therapy was determined in 36 (31.3\%) patients. Severe intoxications cases affecting neurologic and respiratory systems were diagnosed in 12 (10.4\%) patients and no patient died. CD4 cell counts $\leq 500$ cells (O.R.:4.2; C.I.95\%:1.2-14.6) and mental health disorders (O.R.: 2.9; C. 1 95\%: 0.8-9.9) were associated with severe acute drug intoxications in the bivariate analyses.
\end{abstract}

*Correspondence: rperello@clinic.cat

2 Emergency Department, Hospital Clínic, C. de Villarroel, 170,

08036 Barcelona, Spain

Full list of author information is available at the end of the article

(c) The Author(s) 2022. Open Access This article is licensed under a Creative Commons Attribution 4.0 International License, which permits use, sharing, adaptation, distribution and reproduction in any medium or format, as long as you give appropriate credit to the original author(s) and the source, provide a link to the Creative Commons licence, and indicate if changes were made. The images or other third party material in this article are included in the article's Creative Commons licence, unless indicated otherwise in a credit line to the material. If material is not included in the article's Creative Commons licence and your intended use is not permitted by statutory regulation or exceeds the permitted use, you will need to obtain permission directly from the copyright holder. To view a copy of this licence, visit http://creativecommons.org/licenses/by/4.0/. The Creative Commons Public Domain Dedication waiver (http://creativeco mmons.org/publicdomain/zero/1.0/) applies to the data made available in this article, unless otherwise stated in a credit line to the data. 
Conclusions: Chemsex-related intoxications are an increasing clinical problem in people living with HIV. Chemsex should be routinely screened and addressed in clinical practice, particularly for people with mental illness and low CD4 cell counts, who are at higher risk for severe intoxications.

Keywords: PLHIV, Chemsex, Intoxications, Drugs, Mental illness

\section{Background}

Chemsex is defined as the intentional use of psychoactive or non-psychoactive drugs before or during sex to facilitate, prolong, and/or intensify sexual experience. Drugs can also be injected, in a behaviour called 'slamming' or 'slamsex' $[1,2]$. It is practiced mainly by men who have sex with men (MSM) [1,2], and the most common used drugs are crystal methamphetamine, gammahydroxybutyric acid (GHB)/gamma-butyrolactone (GABA) and mephedrone $[1,2]$.

The prevalence of chemsex ranges from 3 to $29 \%$ according to the measurement and recruitment methods used [3-7]. However, it has been found that people living with HIV (PLHIV) may practice chemsex more frequently than the ones who have HIV negative test results or with an unknown status [3-7].

Nevertheless, chemsex drugs use is associated with serious consequences on the health of PLHIV [5]. First, drug use may interfere with daily routine and consequently with adherence to antiretroviral therapy increasing the risk of virologic failure [8-10]. Second, drugs use is associated to sex without condoms and high-risk sexual behaviours [11] facilitating transmission of hepatitis $C$ virus and other sexual transmitted infections [11-14]. Third, substance-using sexual and gender minorities engaging in chemsex are at increased risk of sexual violence [15-17]. Finally, chemsex drugs have the potential to interact with antiretroviral drugs because they are metabolized, at least in part, by the CYP450 system, which could lead to affect antiviral plasma concentrations or increase recreational drugs toxic effects $[18,19]$ resulting in acute intoxications [20-25]. Specifically, boosting agents ritonavir and cobicistat have moderate inhibitory effects on the metabolism of methamphetamine and mephedrone and low with GHB. It is important to note that the extent of the interaction varies according to the route of administration, as these drugs can be administrated by different ways, including oral, nasal, intravenous and rectal $[18,19]$.

However, clinical data available come from case series reported due to the ethical impossibility of conducting clinical trials under these clinical circumstances.

Therefore, it is necessary to describe the incidence and clinical factors related to acute chemsex intoxications with the purpose of identifying patients at higher risk, evaluating the impact of drug-drug interactions and stablishing preventive measures.

The aims of this study were to describe the severity and related factors of acute chemsex intoxications in PLHIV admitted to an emergency department.

\section{Methods}

This retrospective study was conducted in the emergency department of a teaching hospital of Barcelona (Spain) from January, 2018 to December, 2020.

All PLHIV who were admitted for acute drug intoxication associated to chemsex in the emergency department during the study period were included in the study. For the purpose of the study, demographic and clinical characteristics, including mental health disorders, which were diagnosed according to the DSM-V previously to the admission, were extracted from the patients' medical records and categorized to maintain anonymity where necessary. Chemsex was defined as the intentional sex under the influence of one or more of the next drugs: crystal methamphetamine, gammahydroxybutyric acid (GHB)/gamma-butyrolactone (GABA) or mephedrone [1]. Poly-drug use was considered as the use of two or more chemsex drugs. Acute drug intoxication was defined as a transient clinical condition following the administration of chemsex drugs, resulting in disturbances in level of consciousness, cognition, perception, affect or behavior, or other psychophysiological functions and responses [26]. Severe acute intoxications were defined according to the Poisoning Severity Score [27]. Chemsex drug detection tests were performed by immunoassay (DRI ${ }^{\circledR}$; Abbott Diagnostics, Texas, USA), and confirmation and detection of interference by gas chromatography and mass spectrometry (GC-MS) (Agilent 5975/68901, Santa Clara, CA, USA). A specific method was used for the detection of GHB [28]. Potential interactions of antiretrovirals with chemsex drugs were based on in vitro effects of antiretrovirals on the cytochrome P450 and categorized as induction, for efavirenz, nevirapine or etravirine, but not for ritonavir-boosted protease inhibitors; inhibition, for ritonavir or cobicistat boosted protease inhibitors and elvitegravir regardless of other drugs included in the regimen; or neutral for other regimens excluding ritonavir/cobicistat or efavirenz/nevirapine/ etravirine but including rilpivirine, raltegravir, dolutegravir, or maraviroc based regimens $[18,19]$. 
The primary end point of the study was the incidence of severe acute chemsex drug intoxications, defined as the number of severe acute intoxications/number of total intoxications quotient, and related factors.

Descriptive statistics were expressed as mean, standard deviation, median and range for continuous variables and absolute frequencies and percentages for categorical variables. The chi-square test was used to compare categorical variables and Mann-Whitney $U$ test for continuous variables that did not follow a normal distribution. Bivariate analyses was used to assess clinical factors associated to severe acute intoxications. A $p$ value $<0.1$ was considered significant. Analyses were made using SPSS software, version 17.0.0 (Chicago, Illinois).

The study complied with the ethical statements in the Declaration of Helsinky (64th General Assembly, Fortaleza, Brazil, October 2013) and was approved by the local Ethics Committee (Ethics Committee for Drug Research, Clinic Hospital Clinic, Barcelona, Spain, HCB2021-004). The ethics committee waived the need of informed consent due to the retrospective design of the study.

\section{Results}

During the study period 119 patients were admitted to the emergency department for an acute chemsex drug intoxication, of whom 115 were PLHIV: 15 (13.1\%) in 2018, $32(27.8 \%)$ in 2019 and 68 (59.1\%) in 2020.
Clinical characteristics of the patients included in the study are shown in Table 1. Most of the individuals were Spanish citizen men who have sex with men and all patients had stable housing. Main mental health disorders were: personality disorders in 19 patients, anxiety and mood in 11 and bipolar in 2. Immunoglobulin G antibodies against hepatitis $C$ virus antigens were positive in 13 patients and hepatitis $C$ virus RNA was positive in 2 patients.

HIV-1 RNA suppression was observed in 99(86.1\%) patients with a median CD4 cell count of 624 cells $/ \mathrm{mm} 3$. Integrase inhibitors were the main antiviral group used for HIV treatment.

Poly-drug use was observed in 51(44.3\%) patients and the main drugs detected were: methamphetamine in 75 (65.2\%) cases, GHB in 68 (59.1\%), cocaine in 40 (34.7\%), ketamine in $12(10.4 \%)$, amyl nitrite in $12(10.4 \%)$ and mephedrone in 7 (6.1\%) and alcohol in 19(16.5\%).

One third of the antiretroviral-based regimens had a potential inhibition drug-drug interaction: elvitegravir/cobicistat with methamphetamine in 13 cases, with mephedrone in 4, with GHB in 3, with cocaine in 2 and ketamine in 1; and darunavir/cobicistat with methamphetamine in 10, with mephedrone in 2 and with GHB in 1.

Severe acute chemsex drug intoxications were diagnosed in $12(10.4 \%)$ patients, presenting as neurological alterations in the form of coma with respiratory failure.

Table 1 Clinical characteristics of the 115 people living with HIV with acute intoxication associated to chemsex

\begin{tabular}{|c|c|c|c|c|}
\hline Characteristics & Total & Severe acute intoxication & $\begin{array}{l}\text { Non-severe acute } \\
\text { intoxication }\end{array}$ & $p$ \\
\hline $\mathrm{n}$ & 115 & $12(10.4 \%)$ & $103(89.6 \%)$ & \\
\hline Age $^{1}$ & $35.6 \pm 7$ & $35.3 \pm 8$ & $35.4 \pm 7$ & 0.94 \\
\hline MSM & $111(96.5 \%)$ & $12(100 \%)$ & $99(89.5 \%)$ & 0.64 \\
\hline Bisexual men & $4(3.5 \%)$ & $0(0.0 \%)$ & $4(10.5 \%)$ & \\
\hline Spanish citizen & 107 (93.0\%) & $11(91.7 \%)$ & $96(93.2 \%)$ & 0.84 \\
\hline Stable housing & $115(100 \%)$ & $12(100 \%)$ & $103(100 \%)$ & 1 \\
\hline Mental health disorder & $32(27.8 \%)$ & $7(58.3 \%)$ & $25(24.3 \%)$ & 0.02 \\
\hline IgG antibodies hepatitis $C$ & $13(11.3 \%)$ & $1(9.1 \%)$ & $12(13.1 \%)$ & 0.89 \\
\hline \multicolumn{5}{|l|}{ CD4 lymphocyte } \\
\hline total $^{2}$ & $624(500-765)$ & $518(395-639)$ & $630(512-800)$ & 0.04 \\
\hline$\geq 500 \mathrm{cells} / \mathrm{mm} 3$ & $89(77.3 \%)$ & $6(50 \%)$ & $83(80.6 \%)$ & 0.03 \\
\hline $\mathrm{VIH}-1 \mathrm{RNA}<50$ copies $/ \mathrm{mL}$ & $99(86.1 \%)$ & $9(75.0 \%)$ & $90(87.4 \%)$ & 0.22 \\
\hline$|G|$ & $78(67.8 \%)$ & $9(75 \%)$ & $69(67.0 \%)$ & \\
\hline NNRTI & $22(19.1 \%)$ & $1(8.3 \%)$ & $21(20.4 \%)$ & 0.53 \\
\hline $\mathrm{Pl}$ & $15(13.0 \%)$ & $2(16.7 \%)$ & $13(12.6 \%)$ & \\
\hline Inhibitor drug-drug interactions & $36(31.3 \%)$ & $4(33.3 \%)$ & $32(31.1 \%)$ & 0.55 \\
\hline Poly-drug use & $51(44.3 \%)$ & $5(41.6 \%)$ & $46(44.6 \%)$ & 0.84 \\
\hline
\end{tabular}

Data are presented as No. (\%) unless otherwise indicated.1: Data presented as mean \pm standard deviation. 2: Data presented as median and interquartile range Abbreviations: MSM Men who have sex with men, Ig Immunoglobulin, $m L$ Mililiter, RNA Ribonucleic acid, IGI Integrase inhibitors, NNRTI Non-nucleoside reverse transcriptase inhibitor, PI Protease inhibitor 
No patient died. The bivariate analysis of factors associated to severe intoxications is shown in Table 2. CD4 cell count $\leq 500$ cells and mental health disorder were associated to severe acute drug intoxications in the bivariate analysis. No specific chemsex drugs were associated to the severity of acute intoxications.

\section{Discussion}

The results of this observational study showed that the number of acute chemsex drug intoxications increased over the study period and that the severity of the intoxications was higher in people with low CD4 cell count and mental health disorders.

Immune impairment was the main factor associated with the severity of acute intoxications in this study. In this sense, cocaine, alcohol, cannabinoids and ketamine, which are not primarily considered to be immunosuppressive agents, have been described to modulate the humoral and cellular immune response in humans or animals $[29,30]$. Otherwise, the low CD4 count could only be indicative of a worse overall clinical situation, and therefore point to those individuals more susceptible to the effects of chemsex drugs, similar to the adverse event of antiretroviral therapy, which progressively increase with decline in CD4 cell count [31]. Finally, this association could only reflect poor adherence to antiretroviral therapy and lower immune recovery. However the observational design of the study does not allow to contrast these hypothesis.

Table 2 Bivariate analysis of clinical factors associated with acute severe chemsex intoxications

\begin{tabular}{lll}
\hline Characteristics & O.R. & $\boldsymbol{p}$ \\
\hline Age & $1.1(0.9-1.11)$ & 0.61 \\
MSM & & \\
$\quad$ Bisexual men & $1.1(0.1-22.2)$ & 0.93 \\
Spanish citizen & $0.8(0.1-7.1)$ & 0.84 \\
Stable housing & $0.12(0.1-6.3)$ & 0.29 \\
Mental health disorder & $2.9(0.8-9.9)$ & 0.08 \\
IgG antibodies hepatitis C & $0.7(0.1-5.8)$ & 0.77 \\
CD4 lymphocyte & & \\
$\quad<500$ cells/mm3 & $4.2(1.2-14.6)$ & 0.02 \\
VIH-1 RNA <50 copies/mL & $0.4(0.1-1.8)$ & 0.25 \\
IGl & 1 & \\
NNRTI & $0.8(0.1-13.7)$ & 0.90 \\
PI & $3.4(0.3-35.9)$ & 0.31 \\
Inhibitor drug-drug interactions & $1.1(0.3-3.9)$ & 0.87 \\
Poly-drug use & $0.9(0.3-2.9)$ & 0.62 \\
\hline
\end{tabular}

Abbreviations: O.R. Odds ratio, MSM Men who have sex with men, IgG Immunoglobulin, $m L$ Mililiter, RNA Ribonucleic acid, IGI, Integrase inhibitors, NNRTI Non-nucleoside reverse transcriptase inhibitor, PI Protease inhibitor
The other factor related to the severity of intoxications was the mental illness. This association is relevant as its prevalence in PLHIV are higher than the general population [32-35] as a result of the bidirectional relationship between both conditions [36, 37]. Moreover, PLHIV with mental health disorders often have substance use disorders [38, 39], and the co-occurrence of these conditions impact negatively on the clinical outcomes and the patient's quality of life [34-36]. In this sense, the severity of acute drug intoxications observed in patients with mental health disorders in this study could be explained by other drug-drug interactions between chemsex drugs and psychiatric drugs used for the treatment of mental health disorders [40]. Nevertheless, the association of mental disorders with the severity of intoxications highlights the importance of checking and addressing routinely the use of drugs in PLHIV, particularly in whose with mental health disorders [41].

It is also important to comment that drug-drug inhibitory interactions were not associated with the severity of intoxications in this study. Cobicistat or ritonavir boosted antiviral regimens are potent inhibitors of drugs metabolism via the cytochrome P450, particularly the 3A4 isoenzyme, resulting in high plasma drug concentrations of ketamine and erectile dysfunction drugs when are coadministrated $[18,19]$. Instead, cobicistat or ritonavir boosted antiviral regimens are weak inhibitors of the cytochrome P450 2D6 isoenzyme, and therefore, it is not expected an increasing in plasma concentrations of GHB, mephedrone or methamphetamine $[18,19]$. In addition GHB and methamphetamine were the main recreational drugs used, while ketamine and dysfunction erectile drugs were used in a small proportion of patients, which could justify the low percentage of severe intoxications observed in this study.

However, this study revealed that one third of the patients had a possible drug interaction, so clinicians should be aware of the most relevant interactions and switch antiretroviral treatment with lower propensity for drug interactions based on the pharmacokinetics of antiretrovirals and chemsex drug use patterns $[18,19]$.

The study had some limitations, namely the small number of patients included and lack of a non-PLHIV group due to the low number of non PLHIV admitted to the emergency department for chemsex associated intoxications during the follow-up. Moreover substance use pattern was not evaluated, which could have affected the risk of severe intoxications. However, cases of acute chemsex drug intoxication were well documented by urine drug testing and a long follow-up was employed to evaluate incidence changes over time.

Nevertheless, the study has some implications. The increasing number of chemsex drugs intoxications 
observed in the study reflects a local deficit in Spanish health responses to chemsex harms. In fact, chemsex care continues to focus on external heroin-based clinics, where men who have sex with men do not attend because they do not feel identified, or community organizations, many of which are not connected to the Spanish health network [42]. As chemsex is interlinked with other sexual and mental health issues, it is essential integrated approaches between different health care services, including HIV/sexual health, psychology, drug and addiction services, to be able to value and offer treatment to chemsex [43].

\section{Conclusions}

In conclusion, acute chemsex drug intoxications in PLHIV are an increasing clinical problem with potential life-threatening events, particularly for whose with low CD4 cell counts and mental health disorders. Chemsex should be routinely screened and properly addressed in the clinical practice, through a multidisciplinary approach, including medical and psychosocial services.

\section{Acknowledgements}

No.

\section{Authors' contributions}

$R P$ and $G V$ were the chairmans. E S, E M were the responsibilities of laboratory diagnosis validation, $A$ I, A L, J C did the statistical results, A L, A M, ALD collected the patients. The author(s) read and approved the final manuscript. All authors have confirmed the maintenance of confidentiality and respect for patients' rights.

\section{Funding}

The authors declare that no funding has been received.

\section{Availability of data and materials}

The datasets generated and/or analysed during the current study are not publicly available due to the fact that we do not wish to share our dataset since they are part of patients' medical history. However, they are available from the corresponding author on reasonable request.

\section{Declarations}

\section{Ethics approval and consent to participate}

The study complied with the ethical statements in the Declaration of Helsinky (64th General Assembly, Fortaleza, Brazil, October 2013) and was approved by the local Ethics Committee (Ethics Committee for Drug Research, Clinic Hospital Clinic, Barcelona, Spain, HCB-2021-004). The Ethics Committee for Drug Research, Clinic Hospital Clinic, Barcelona, Spain waived the need of informed consent due to the retrospective design of the study.

\section{Consent for publication}

Not applicable.

\section{Competing interests}

The authors declare that they have no competing interests.

\section{Author details}

${ }^{1}$ Drug addiction Unit, Hospital del Mar, Parc de Salut Mar Consortium, Barcelona, Spain. ${ }^{2}$ Emergency Department, Hospital Clínic, C. de Villarroel, 170, 08036 Barcelona, Spain. ${ }^{3}$ Infectious Diseases Department, Hospital Clínic, Barcelona, Spain
Received: 19 June 2021 Accepted: 9 February 2022

Published online: 18 February 2022

\section{References}

1. McCall H, Adams N, Mason D, Willis J. What is chemsex and why does it matter? BMJ. 2015;351:h5790. https://doi.org/10.1136/bmj.h5790 PMID: 26537832.

2. Giorgetti R, Tagliabracci A, Schifano F, Zaami S, Marinelli E, Busardò FP. When "Chems" meet sex: a rising phenomenon called "ChemSex". Curr Neuropharmacol. 2017;15(5):762-70.

3. Sewell J, Miltz A, Lampe FC, Cambiano V, et al. Attitudes to and understanding of risk of acquisition of HIV (AURAH) study group. Poly drug use, chemsex drug use, and associations with sexual risk behaviour in HIVnegative men who have sex with men attending sexual health clinics. Int J Drug Policy. 2017:43:33-43. https://doi.org/10.1016/j.drugpo.2017.01. 001.

4. Curtis TJ, Rodger AJ, Burns F, Nardone A, Copas A, Wayal S. Patterns of sexualised recreational drug use and its association with risk behaviours and sexual health outcomes in men who have sex with men in London, UK: a comparison of cross-sectional studies conducted in 2013 and 2016. Sex Transm Infect. 2020;96:197-203.

5. Maxwell S, Shahmanesh M, Gafosc M. Chemsex behaviours among men who have sex with men: a systematic review of the literature. Int I Drug Policy. 2019;63:74-89.

6. Sewell J, Cambiano V, Speakman A, et al. Changes in chemsex and sexual behaviors over time, among a cohort of MSM in London and Brighton: findings from the AURAH2 study. Int J Drug Policy. 2019;68:54-61.

7. Hampel B, Kusejko K, Kouyos RD, Böni J, Flepp M, Stöckle M, et al. Chemsex drugs on the rise: a longitudinal analysis of the Swiss HIV cohort study from 2007 to 2017. HIV Med. 2020;21:228-39.

8. Hinkin $\mathrm{CH}$, Barclay TR. Drug use and medication adherence among HIV-1 infected individuals. AIDS Behav. 2010;11:185-94.

9. Kalichman SC, Kalichman MO, Cherry C, et al. Intentional medication nonadherence because of interactive toxicity beliefs among HIV-positive active drug users. J Acquir Immune Defic Syndr. 2015;70:503-9.

10. O'Halloran C, Rice B, White E, Desai M, Dunn DT, McCormack S, et al. Chemsex is not a barrier to self-reported daily PrEP adherence among PROUD study participants. Int J Drug Policy. 2019;74:246-54. https://doi. org/10.1016/j.drugpo.2019.10.007.

11. Pufall EL, Kall M, Shahmanesh M, Nardone A, Gilson R, Delpech V, et al. Positive voices study group. Sexualized drug use ('chemsex') and high-risk sexual behaviours in HIV-positive men who have sex with men. HIV Med. 2018;19(4):261-70. https://doi.org/10.1111/hiv.12574.

12. González-Baeza A, Dolengevich-Segal H, Pérez-Valero I, et al. Sexualized drug use (Chemsex) is associated with high-risk sexual behaviors and sexually transmitted infections in HIV-positive men who have sex with men: data from the U-SEX GESIDA 9416 study. AIDS Patient Care STDs. 2018:32:112-8

13. Pakianathan M, Whittaker W, Lee MJ, Avery J, Green S, Nathan B, Hegazi A. Chemsex and new HIV diagnosis in gay, bisexual and other men who have sex with men attending sexual health clinics. HIV Med. 2018. https:// doi.org/10.1111/hiv.12629.

14. Guerras JM, Hoyos Miller J, et al. Association of Sexualized Drug use Patterns with HIV/STI transmission risk in an internet sample of men who have sex with men from seven European countries. Arch Sex Behav. 2021;50:461-77.

15. Hibbert MP, Brett CE, Porcellato LA, Hope VD. Psychosocial and sexual characteristics associated with sexualised drug use and chemsex among men who have sex with men (MSM) in the UK. Sex Transm Infect. 2019;95(5):342-50

16. Wilkerson JM, Di Paola A, Nieto D, Schick V, Latini DM, Braun-Harvey $D$, et al. Sexual violence and Chemsex among substance-using sexual and gender minorities in Texas. Subst Use Misuse. 2021;56(14):2141-50. https://doi.org/10.1080/10826084.2021.1975743.

17. Finnerty F, Fitzpatrick C, Stockwell S, Richardson D. The changing face of male sexual assault: recreational drug use and multiple assailants. Sex Transm Infect. 2019;95(7):550. 
18. Kumar S, Rao PS, Earla R, Kumar A. Drug-drug interactions between antiretroviral therapies and drugs of abuse in HIV systems. Expert Opin Drug Metab Toxicol. 2015;11:343-55.

19. Bracchi M, Stuart D, Castles R, Khoo S, Back D, Boffito M. Increasing use of 'party drugs' in people living with HIV on antiretrovirals: a concern for patient safety. AIDS. 2015;29:1585-92.

20. Henry JA, Hill IR. Fatal interaction between ritonavir and MDMA. Lancet. 1998;352:1751-2.

21. Harrington RD, Woodward JA, Hooton TM, Horn JR. Life-threatening interactions between HIV-1 protease inhibitors and the illicit drugs MDMA and gamma-hydroxybutyrate. Arch Intern Med. 1999;159:2221-4.

22. Hales G, Roth N, Smith D. Possible fatal interaction between protease inhibitors and methamphetamine. Antivir Ther. 2000;5(1):19 PMID: 10846588.

23. Papaseit E, Vázquez A, Pérez-Mañá C, et al. Surviving life-threatening MDMA (3,4-methylenedioxymethamphetamine, ecstasy) toxicity caused by ritonavir (RTV). Intensive Care Med. 2012;38:1239-40.

24. Kobayashi M, Takata Y, Goseki Y, et al. A sudden cardiac death induced by sildenafil and sexual activity in an HIV patient with drug interaction, cardiac early repolarization, and arrhythmogenic right ventricular cardiomyopathy. Int J Cardiol. 2015 Jan;20(179):421-3. https://doi.org/10.1016/j. ijcard.2014.11.090.

25. Hockenhull J, Murphy KG, Paterson S. An observed rise in -hydroxybutyrate-associated deaths in London: evidence to suggest a possible link with concomitant rise in chemsex. Forensic Sci Int. 2017;270:93-7. https://doi.org/10.1016/j.forsciint.2016.11.039.

26. World Health Organization. Management of acute intoxication. Available at: https://www.who.int/substance_abuse/terminology/acute_intox/ en/\#: :text=A\%20transient\%20condition\%20following\%20the,other\% 20psychophysiological\%20functions\%20and\%20responses.

27. Persson HE, Sjöberg GK, Haines JA, Pronczuk de Garbino J. Poisoning severity score. Grading of acute poisoning. J Toxicol Clin Toxicol. 1998:3:205-13.

28. Elian AA. A novel method for GHB detection in urine and its application in drug-facilitated sexual assaults. Forensic Sci Int. 2000;109:183-7.

29. Pillai RM, Watson RR. In vitro immunotoxicology and immunopharmacology: studies on drugs of abuse. Toxicol Lett. 1990;53:269-83.

30. Stefanidou M, Loutsidou AC, Chasapis CT, Spiliopoulou CA. Immunotoxicity of cocaine and crack. Curr Drug Abuse Rev. 2011;4:95-7.

31. Moore RD, Fortgang I, Keruly J, Chaisson RE. Adverse events from drug therapy for human immunodeficiency virus disease. Am J Med. 1996;101:34-40.

32. Remien RH, Stirratt MJ, Nguyen N, Robbins RN, Pala AN, Mellins CA. Mental health and HIV/AIDS: the need for an integrated response. AIDS. 2019;33:1411-20.

33. Kendall CE, Wong J, Taljaard M, et al. A cross-sectional, populationbased study measuring comorbidity among people living with HIV in Ontario. BMC Public Health. 2014;14:161. https://doi.org/10.1186/ 1471-2458-14-161.

34. Hobkirk AL, Towe SL, Lion R, Meade CS. Primary and secondary HIV prevention among persons with severe mental illness: recent findings. Curr HIV/AIDS Rep. 2015;12:406-12.

35. Gaynes BN, Pence BW, Eron JJ Jr, Miller WC. Prevalence and comorbidity of psychiatric diagnoses based on reference standard in an HIV+ patient population. Psychosom Med. 2008;70:505-11.

36. Blank MB, Himelhoch SS, Balaji AB, et al. A multisite study of the prevalence of HIV with rapid testing in mental health settings. Am J Public Health. 2014;104:2377-84

37. Nedelcovych MT, Manning AA, Semenova S, Gamaldo C, Haughey NJ, Slusher BS. The psychiatric impact of HIV. ACS Chem Neurosci. 2017:8:1432-4.

38. Hartzler B, Dombrowski F, Crane HM, et al. Prevalence and predictors of substance use disorders among HIV care enrollees in the United States. AIDS Behav. 2017;21:1138-48.

39. Fuster-RuizdeApodaca MJ, Castro-Granell V, Garin N, et al. Prevalence and patterns of illicit drug use in people living with HIV in Spain: a crosssectional study. PLoS One. 2019;14(6):e0211252.

40. Goodlet KJ, Zmarlicka MT, Peckham AM. Drug-drug interactions and clinical considerations with co-administration of antiretrovirals and psychotropic drugs. CNS Spectr. 2019;24:287-312.
41. Berg RC, Amundsen E, Haugstvedt Å. Links between chemsex and reduced mental health among Norwegian MSM and other men: results from a cross-sectional clinic survey. BMC Public Health. 2020;20(1):1785. https://doi.org/10.1186/s12889-020-09916-7.

42. Addressing the chemsex phenomenon. Secretary of the National Plan on AIDS. Ministry of Health. 2020 available at https://www.mscbs.gob.es/ ciudadanos/enfLesiones/enfTransmisibles/sida/chemSex/docs/CHEMS EX._ABORDAJE.pdf

43. Brook G, Church $\mathrm{H}$, Evans $\mathrm{C}$, Jenkinson $\mathrm{N}$, McClean $\mathrm{H}$, Mohammed $\mathrm{H}$, et al 2019 UK National Guideline for consultations requiring sexual history taking : clinical effectiveness group British Association for Sexual Health and HIV. Int J STD AIDS. 2020;31(10):920-38. https://doi.org/10.1177/09564 62420941708 .

\section{Publisher's Note}

Springer Nature remains neutral with regard to jurisdictional claims in published maps and institutional affiliations.
Ready to submit your research? Choose BMC and benefit from:

- fast, convenient online submission

- thorough peer review by experienced researchers in your field

- rapid publication on acceptance

- support for research data, including large and complex data types

- gold Open Access which fosters wider collaboration and increased citations

- maximum visibility for your research: over $100 \mathrm{M}$ website views per year

At BMC, research is always in progress.

Learn more biomedcentral.com/submissions 